\title{
Sialendoscopic management of autoimmune sialadenitis: a review of literature
}

\author{
Trattamento scialendoscopico delle scialoadeniti autoimmuni: \\ revisione della letteratura
A. GALLO'1, S. MARTELLUCCI ${ }^{1}$, M. FUSCONI², G. PAGLIUCA A A. GRECO², A. DE VIRGILIO², M. DE VINCENTIIS²
${ }^{1}$ Department of Surgical Biotechnologies and Science, ENT Section "Sapienza" University of Rome, Italy;
${ }^{2}$ Department of Sensorial Organs, ENT Section "Sapienza" University of Rome, Italy

\begin{abstract}
SUMMARY
Autoimmune diseases of major salivary glands include Sjögren's syndrome and a complex of disorders classified as immunoglobulin G4-related diseases. These pathologies are characterised by an autoimmune reaction mediated by T-helper lymphocytes that targets the ducts of exocrine glands in Sjögren's syndrome and glandular parenchyma in immunoglobulin G4-related diseases. Immunoglobulin G4-related diseases represent recently introduced multi-organ diseases that also involve the salivary glands. However, the morbid conditions once known as Mikulicz's disease and Kuttner's tumour were recently considered as two variants of immunoglobulin G4-related diseases affecting the major salivary glands ( immunoglobulin G4-related sialadenitis). This review briefly summarises the pathogenesis and clinical features of autoimmune diseases of the major salivary glands, focusing on the diagnostic and therapeutic role of sialendoscopy.
\end{abstract}

KEY WORDS: Kuttner Tumour • Mikulicz`s Disease • IgG4 related diseases • IgG4 related sialadenitis • Sjögren’s syndrome • Ductal stenosis $\bullet$ Sialoendoscopy

\section{RIASSUNTO}

Le patologie autoimmuni delle ghiandole salivari maggiori comprendono la sindrome di Sjögren e l'insieme di condizioni morbose raccolte sotto il nome di patologie IgG4-correlate. Tanto la sindrome di Sjögren quanto le patologie IgG4-correlate sono caratterizzate da una reazione autoimmune mediata dai linfociti T-Helper il cui bersaglio è rappresentato dai dotti delle ghiandole esocrine nella sindrome di Sjögren e dal parenchima ghiandolare nelle malattie IgG4-correlate. Queste ultime, di introduzione relativamente recente, coinvolgono solitamente molti organi tra cui le ghiandole salivari. Negli ultimi anni patologie un tempo note come malattia di Mikulicz e tumore di Kuttner sono state classificate come le patologie IgG4-correlate limitate alle ghiandole salivari maggiori e denominate scialoadeniti IgG4-correlate. Questa breve revisione riassume la patogenesi e le principali caratteristiche cliniche delle ghiandole salivari maggiori sottolineando il potenziale ruolo diagnostico e terapeutico delle scialoendoscopia.

PAROLE CHIAVE: Tumore di Kuttner $\bullet$ Malattia di Mikulicz • Patologie IgG4-Correlate $\bullet$ Scialoadeniti IgG4-Correlate $\bullet$ Sindrome di Sjögren $\bullet$ Stenosi Duttale $\bullet$ Scialoendoscopia

Acta Otorhinolaryngol Ital 2017;37:148-154

\section{Introduction}

Salivary gland diseases include neoplasms and non-neoplastic disorders such as viral parotitis, sialolithiasis and chronic non-lithiasic sialadenitis. Autoimmune diseases are responsible for a small share of chronic, non-lithiasic inflammatory disorders of major salivary glands. In these conditions, the parenchyma of salivary glands, salivary ducts, or both represent the target of an attack carried out by the immune system against its own tissues, through autoantibodies and T cells. Sjögren's syndrome (SS) and immunoglobulin G4-related diseases (IgG4-RD) are the main chronic autoimmune sialadenitis ${ }^{12}$.

SS attacks the exocrine glands, specifically the salivary and lacrimal tissue, and CD4+ lymphocytes play the main role in the autoimmune process. IgG4-RD are newly described fibro-inflammatory conditions that often present as nodular lesions that can affect nearly every organ system ${ }^{1}$. In IgG4$\mathrm{RD}$, the target of the autoimmune attack is the connective tissue and the inflammatory cell infiltration is composed of IgG4-positive plasma cells, CD4+ and CD8+ T cells. In recent years, both Mikulicz's disease (MD) and the so-called Kuttner's tumour (KT) were classified in the group of IgG4$\mathrm{RD}$ and considered as variations of IgG4 RD affecting salivary tissue (IgG4-related sialadenitis or IgG4-RS) ${ }^{3}$.

The aim of this review is summarise the characteristics of the autoimmune diseases that affect the salivary glands, analysing the potential role of sialendoscopic techniques in the diagnosis and treatment of these conditions.

\section{Sjögren's syndrome (SS)}

SS may be defined as a chronic autoimmune inflammatory exocrinopathy affecting the salivary and lacrimal glands. 
The dysfunction of exocrine glands is usually accompanied by a multitude of extraglandular manifestations ${ }^{4}$. SS may occur as primary or secondary form. Primary SS, with or without extraglandular involvement, occurs in the absence of another underlying rheumatic disorder, whereas secondary SS is associated with another autoimmune disease, such as systemic lupus erythematosus, rheumatoid arthritis, or scleroderma. Given the overlap of SS with many other rheumatic disorders, it is sometimes difficult to determine whether a clinical manifestation is solely a consequence of SS or is due to one of its overlapping disorders. These primary and secondary types occur with similar frequency, but sicca complex symptoms seem to be more severe in primary form ${ }^{5,6}$.

Primary SS is an autoimmune disorder characterised by lymphocytic infiltrates with destruction of exocrine glands and systemic production of autoantibodies against ribonucleoprotein particles SS-A/Ro and SS-B/La. The infiltrating cells (T- and B-cells, dendritic cells) interfere with salivary production at several points, starting a vicious circle and causing the salivary glands to become sites of chronic inflammation ${ }^{4}$.

Despite extensive studies, the underlying cause of SS and its pathogenesis remains controversial. It is thought that environmental factors can trigger inflammation in individuals with a genetic predisposition, configuring a multifactorial disease ${ }^{7}$.

Primary SS is strongly associated with HLA-DR3 and the linked genes B8, and DQ2, and C4A null gene. Within the primary SS group, those with anti-La represent a subset that show an even more striking association with HLA 3. This suggests that the anti-La-positive patients with SS may be the most homogeneous subgroup, both clinically and immunogenetically. Anti-Ro is associated with DR2 and the linked DQ1 gene, as well as with DR3, and this may reflect the wider diagnostic associations of this antibody. Rheumatoid arthritis with secondary SS is associated with DR4 rather than DR3 ${ }^{8-11}$.

Viruses are viable candidates as environmental triggers, although no single virus has been implicated and the triggering mechanisms is still unknown. Epstein-Barr virus, HTLV-1, human herpesvirus 6, HIV, hepatitis C virus and cytomegalovirus may have a role and clinical manifestations of sicca syndrome are frequently seen in patients infected with HIV, HTLV-1, and hepatitis C ${ }^{12-14}$. Damage and/or cell death due to viral infection may provide triggering antigens to toll-like receptors in or on dendritic or epithelial cells, which, by recognising pathogen-associated patterns, are activated and begin producing cytokines, chemokines and adhesion molecules. As T and B lymphocytes migrate into the gland, they themselves become activated by dendritic and epithelial cells, thereafter acting as antigen-presenting cells. Expressed antigens include SSA/ Ro, SSB/La, alpha-fodrin and beta-fodrin, and cholinergic muscarinic receptors. Dendritic cell triggering by immune complexes formed from SSA-anti-SSA (or other immune complexes) may propagate the ongoing innate and acquired immune activation ${ }^{11-15}$.

SS is one of the most common autoimmune rheumatic diseases with a prevalence around $1 \%$ according to the revised American-European Consensus Group (AECG) criteria ${ }^{16}$. There is general agreement that it is a disease of middle-aged or elderly women (mean age of onset 45-55 years, male/female ratio 1:9) ${ }^{411}$.

Clinically, most individuals with SS present with sicca symptoms (xerophthalmia and xerostomia), that are expression of chronic exocrinopathy. The lack of saliva in the mouth and the absence of a normal 'pool' of saliva underneath the tongue causes an increase in the rate of caries and may promote oral candidosis. In more severe cases, the tongue is atrophic, fissured or even ulcerated. Parotid glands are frequently swollen. Exocrine glands other than the salivary and lacrimal glands may be affected. Dry skin and dry hair are symptoms frequently elicited on direct questioning. About $30 \%$ of patients have diminished vaginal secretions and may present with dyspareunia. Involvement of the gastrointestinal tract leads to reflux oesophagitis or gastritis owing to a lack of protective mucus secretion is also possible ${ }^{4-711}$.

SS is a systemic disease. About $70 \%$ of patients complain of fatigue that may be misdiagnosed whereas arthritis, with characteristics similar to those seen in rheumatoid arthritis, occurs in about $30 \%$ of subjects ${ }^{11}$. The renal features of SS include interstitial nephritis, leading to renal tubular acidosis, and membranous glomerulonephritis due to circulating immune complex disease (more common in the secondary SS). The incidence of significant renal disease of around 5\%, but subclinical renal features of disease rises to around $30 \%{ }^{17}$. Interstitial pneumonitis determined by an interstitial infiltrate of lymphocytes around the bronchioles may cause function abnormalities found in approximately $25 \%$ of patients with SS ${ }^{18}$. Although vasculopathies such as Raynaud's phenomenon and congenital heart block are also frequently observed, these disorders assume minor clinical significance ${ }^{11}$. Conversely, neurological involvement is quite rare (1\%), but may manifest as multiple sclerosis-like syndrome ${ }^{19}$. Finally,it has long been known that patients with primary SS have a 44-fold increased risk of mucosa-associated lymphoid tissue (MALT) type B cell lymphoma ${ }^{20}$.

A number of classification criteria for SS were designed, primarily for clinical research studies, but are also used to guide clinical diagnoses. The revised AECG criteria for classification of Sjögren's syndrome ${ }^{16}$, summarised in Table I, were proposed in 2002 and are the most commonly used criteria for diagnosis of SS. A new set of classification criteria has been developed by the Sjögren's International Collaborative Clinical Alliance (SICCA) investigators and accepted as a provisional criteria set by the American College of Rheumatology (ACR) in $2012^{21}$. Diagnostic workup in the suspicion of SS usually include 
Table I. American-European Consensus Group Classification criteria for Sjögren's syndrome. Diagnosis of primary Sjögren's syndrome requires four of six criteria; in addition, either criterion number 5 or criterion number 6 must be included. Sjögren's syndrome can be diagnosed in patients who have no sicca symptoms if three of the four objective criteria are fulfilled. Secondary Sjögren's syndrome is diagnosed when, in the presence of a connective-tissue disease, symptoms of oral or ocular dryness exist in addition to criterion 3,4 , or 5 .

\begin{tabular}{|c|c|c|}
\hline 1. & Ocular symptoms & $\begin{array}{l}\text { Dry eyes for more than } 3 \text { months } \\
\text { Foreign-body sensation } \\
\text { Use of tear substitutes more than } 3 \text { times daily }\end{array}$ \\
\hline 2. & Oral symptoms & $\begin{array}{l}\text { Feeling of dry mouth } \\
\text { Recurrently swollen salivary glands } \\
\text { Frequent use of liquids to aid swallowing }\end{array}$ \\
\hline 3. & Ocular signs & $\begin{array}{l}\text { Schirmer test performed without anesthesia }(<5 \mathrm{~mm} \text { in } 5 \mathrm{~min}) \\
\text { Positive vital dye staining results }\end{array}$ \\
\hline 4. & Oral signs & $\begin{array}{l}\text { Abnormal salivary scintigraphy findings } \\
\text { Abnormal parotid sialography findings } \\
\text { Abnormal sialometry findings (unstimulated salivary flow }<1.5 \mathrm{~mL} \text { in } 15 \mathrm{~min} \text { ) }\end{array}$ \\
\hline 5. & \multicolumn{2}{|c|}{ Positive minor salivary gland biopsy findings (focus score $\geq 1$ ) } \\
\hline 6 & Positive anti-SSA & nti-SSB antibody results \\
\hline
\end{tabular}

Exclusions: any patient with past head and neck radiation treatment, hepatitis $\mathrm{C}$ infection, acquired immunodeficiency disease (AIDS), pre-existing lymphoma, sarcoidosis, graft versus host disease, use of anticholinergic drugs.

the blood tests listed in the revised AECG criteria. Furthermore, patients with SS frequently present leucopenia, thrombocytopenia, high ESR and anti-nuclear antibodies. The classical histological feature of SS at minor salivary gland biopsy is of at least one 'focus' of 50 or more (predominantly CD4+) T lymphocytes per high-powered field clustered around a salivary duct (periductal focal lymphocytic infiltrates). Histology reports sometimes describe a generalised scattering of inflammatory cells across the gland usually described as a 'chronic sialadenitis'. The report may conclude that this is 'compatible with SS'. In fact, chronic sialadenitis can be found in normal individuals and this should be classed as a negative biopsy ${ }^{1471116}$. AECG criteria order to objectively assess xerophthalmia through simple, economic tests such as Rose Bengal staining and the Schirmer test, which can be used to strongly support or refute the suspicion of SS ${ }^{22}$. Conversely, the tests recommended to objectify the signs of xerostomia, except for the poor standardised sialometry, are particularly expensive (salivary scintigraphy) and not very specific (sialography) imaging techniques. Sialographic changes in parotid glands affected by SS were accurately described and, with regards to chronic sialadenitis, classified into punctate, globular, cavitary and destructive sialectasia of the acinar and ductal system. These four sialectasic changes are thought to represent increasing glandular damage caused by an autoimmune reaction ${ }^{23}$. Sialendoscopy, according to AECG criteria, is not listed as a recommended examination to assess salivary gland involvement in SS. The reason for this exclusion is probably due to historical reasons: the revised AECG criteria, in fact, date to 2002 whereas sialendoscopy still represents a relatively new procedure. However, this technique allows endoscopic transluminal visualisation of major salivary glands and offers a mechanism for diagnosing and treating both inflammatory and obstructive pathologies related to the ductal system, and thus like sialography potentially adequate to recognise the ductal abnormalities accompanying $\mathrm{SS}^{24}$.

In the literature, there is little experience about the role of sialendoscopy in SS. Some authors report the presence of hyperaemia at the level of main and the second-order salivary ducts, with evidence of a vascular pattern demonstrating perivascular inflammation and congestion ${ }^{25}$. It is possible that this endoscopic appearance, also observed in recurrent parotitis, could characterise the initial phases of SS, whereas the pale, little vascularised appearance of the ductal wall expresses the subsequent progression of the disease, in which parenchymal tissue is replaced by fibrosis ${ }^{24} 25$. Obstructive mucous plugs are frequently observed in the ductal tree. The presence of these obstructions causes saliva stagnation and inflammation upstream of the obstruction, which is probably responsible for the occasional parotid swelling and pain ${ }^{25} 26$. However, stricture formation was found to be the major cause of ductal obstruction by other authors. Jager, et al. and De Luca, et al. reported the presence of stricture in the majority of salivary glands affected by SS explored in their study ${ }^{27} 28$. Microlithiasis, related to the subsequent inflammatory episodes ${ }^{29}$, is observed mainly in the advanced stages of the disease in which the fibrous replaced and subverted the entire gland. Our research group is currently investigating a possible role of sialendoscopy in diagnosis of SS by analysing the expression of IL-17 and IL-23 in saliva and ductal lavage collected during the surgical procedure. The therapy for SS is based on drugs aimed to modulate the autoimmune response. Traditional immunomodulatory drugs such as low-dose steroids, methotrexate, ciclosporin and azathioprine show no benefit, while there is some evidence to support the use of hydroxychloroquine sulphate, although there is no evidence of a direct effect on salivary or lacrimal flow ${ }^{60-32}$. Thus, although biologic 
agents represent promising treatments ${ }^{33-35}$, the current management of xerostomia and xerophthalmia is still based on topical treatments (tear and saliva substitutes) ${ }^{36}$ and sialogogues such as pilocarpine and cevimeline ${ }^{37-39}$.

During sialendoscopy, a semi-rigid miniaturised endoscope is inserted into the salivary duct after dilating the papilla and driven in the ductal system under constant irrigation ${ }^{40}$. Sterile saline solution is the fluid of choice for the irrigation of salivary ducts, but corticosteroid solutions can also be used ${ }^{24}{ }^{40-42}$ Thus, a diagnostic procedure alone causes relevant dilation of the entire ductal system. On the other hand, the use of interventional sialendoscope with working channels allows the concomitant treatment of strictures, mucus plugs and sialoliths, contributing to alleviate complaints in patients affected by inflammatory disease ${ }^{24} 43-45$. Recent clinical experience suggested that sialendoscopy may alleviate the oral symptoms of SS by restoring salivary function ${ }^{25-28}$. Jager, et al. conducted a randomised study of 20 patients with SS oral symptoms who were randomly assigned to the nonintervention control group or to the sialendoscopy group. In patients undergoing sialendoscopy, unstimulated and stimulated saliva flow, Clinical Oral Dryness Score, Xerostomia Inventory Score, and EULAR Sjogren's Syndrome Patient Reported Index score showed a significant improvement of symptoms at 1 and 8 weeks after the procedure ${ }^{27}$. Although a positive effect of sialendoscopy on xerostomia cannot be assessed with a few, small case series, these promising results suggest that sialoendoscopy could be a viable technique to treat obstructive salivary gland diseases related to SS that is refractory to conventional management.

\section{IgG4-related sialadenitis (IgG4-RS)}

IgG4-RD are newly described fibro-inflammatory conditions that often presents as tumefactive lesions affecting several districts. Hamano, et al. first recognised IgG4-RD in 2001, after a connection between elevated serum IgG4 levels and inflammatory mass lesions in the pancreas causing autoimmune pancreatitis ${ }^{46}$. However, an initial consensus statement regarding diagnosis of IgG4-RD was reached only in 2011 during the first international symposium for IgG4-RD ${ }^{47}$.

The head and neck region is the second most common site for presentation of IgG4-RD after the pancreas and some pseudotumoural diseases of unknown pathogenesis, including MD and KT, have been attributed to IgG4-RD during the last 10 years ${ }^{48-55}$. Identification of IgG4-positive plasma cells in both KT and MD propelled renewed interest in these diseases, and fueled re-analyses of the classification of inflamed salivary glands ${ }^{56}$.

The exact aetiology of IgG4-RS is unknown and no known role of the IgG4 molecule has been identified. IgG4 itself normally represents the smallest fraction of IgG subclasses $(<5 \%)$. It has an amino acid variance in the hinge region allowing it to split and randomly combine with other half molecules, creating asymmetric bispecific antibodies with two different antigen-binding sites. For this special feature, IgG4 scarcely forms immune complexes, binds Fc-receptors and complements component with low affinity. Thus, its ability to initiate immune responses is limited ${ }^{23}$. It is postulated that the inflammatory and fibrotic processes that drive IgG4-RS are propagated by a combination of $\mathrm{T}$ helper (Th) 2 cells and regulatory T cells (Treg cells). This is contrary to most autoimmune disorders where polarised Th1 and/or Th17 subsets are responsible for the inflammatory process ${ }^{2347}$.

Clinical data on IgG4-RS are increasingly reported. Currently, it is believed that this condition preferentially affects middle-aged males presenting with persistent parotid and/or submandibular gland swelling, unilaterally or bilaterally.

The disorder that was identified by Kuttner in $1896^{57}$ commonly involves one or both submandibular glands, clinically presenting as hard tumour-like masses with tendency to nodular swelling that can be confounded with malignant forms. The disease is often associated with microlithiasis. Histological sections reveal preservation of the lobular architecture, marked lymphoplasmacytic inflammation, large irregular lymphoid follicles with expanded germinal centers and acinar atrophy without prominent lymphoepithelial lesions. Characteristically, prominent cellular interlobular fibrosis due to activated fibroblasts and infiltration of lymphocytes and IgG4-positive-stained plasma cells is observed. Eosinophil infiltration and obliterative phlebitis are frequent ${ }^{56}$.

$\mathrm{MD}$, first described in $1888^{58}$, refers to idiopathic, bilateral, painless, symmetrical and persistent swelling of the lacrimal, parotid and submandibular glands. Because MD and primary-SS are histologically similar, MD has long been considered as a subtype of SS. Upon haematoxylin-eosin staining, lacrimal or salivary gland specimens from MD showed severe mononuclear cell infiltration and lymphoid follicles around the ductal and acinar cells. The infiltration of numerous IgG4-positive plasmacytes near acinar and ductal cells and around lymphoid follicles allows differentiating MD from SS ${ }^{51}$. Therefore, the presence of IgG4-positive plasmacytes in the inflammatory infiltration suggests that MD and KT are only two different phenotypes of IgG4-RS. A comparison between clinical and histological features of the two phenotypes of IgG4-RS and SS is summarised in Table II.

Clinically, xerostomia is inconstant in IgG4-RS, involving approximately $30 \%$ of patients. Autoimmune pancreatitis, sclerosing cholangitis and asthma are frequently associated conditions (15-30\%). Lacrimal gland involvement, as well as sinonasal disorders and cervical lymphadenopathy (70\%), are frequent coexisting conditions ${ }^{3}$.

Imaging studies of salivary glands show a pattern of nonspecific features in MD phenotype of IgG4-RS. On US 
Table II. Comparison between SS and IgG4-RS

\begin{tabular}{|c|c|c|c|c|c|}
\hline \multirow[t]{2}{*}{ Features } & & \multirow[t]{2}{*}{ SS } & \multicolumn{3}{|c|}{$\lg G 4-R S$} \\
\hline & & & MD phenotype & & KT phenotype \\
\hline \multirow[t]{6}{*}{ Clinical } & Gender (female:male) & $9: 1$ & & $1: 2.5$ & \\
\hline & Glands involvement & $\begin{array}{l}\text { Both parotids and } \\
\text { submaxillary glands }\end{array}$ & $\begin{array}{l}\text { Both parotids and } \\
\text { submaxillary glands }\end{array}$ & & submaxillary glands \\
\hline & Bilateral/unilateral & Bilateral & Bilateral & & Often unilateral \\
\hline & Appearance & $\begin{array}{l}\text { Usually transient } \\
\text { swelling }\end{array}$ & $\begin{array}{c}\text { Persistent symmetrical } \\
\text { swelling }\end{array}$ & & Persistent nodular swelling \\
\hline & Salivary impairment & Severe & & Mild & \\
\hline & Response to steroids & Limited & & Good & \\
\hline \multirow[t]{3}{*}{ Histological } & Fibrosis & Inconstant, mild & & Constant, intense & \\
\hline & Obliterative phlebitis & Absent & & frequent & \\
\hline & lgG4+ plasmacytes & Absent & & $>30-50 \mathrm{hpf}$ & \\
\hline \multirow[t]{3}{*}{ Serological } & Serum IgG4 levels & Normal & & High & \\
\hline & Serum lgE levels & Normal & & High & \\
\hline & $\begin{array}{l}\text { Anti-Ro(SSA)/ } \\
\text { Anti-La(SSB) }\end{array}$ & High rate & & Absent & \\
\hline Imaging & Ultrasound & $\begin{array}{c}\text { Inhomogeneity } \\
\text { hypoechoic areas and } \\
\text { hyperechoic lines and } \\
\text { spots }\end{array}$ & $\begin{array}{l}\text { Inhomogeneity hypoechoic } \\
\text { areas and hyperechoic } \\
\text { lines and spots }\end{array}$ & & $\begin{array}{c}\text { Nodular, smooth contour mass } \\
\text { with hypoechoic foci scattered } \\
\text { against a heterogeneous } \\
\text { background. }\end{array}$ \\
\hline
\end{tabular}

examination of the affected glands, hypoechoic areas with hyperechoic lines creating a reticular pattern that is a common finding in patients affected by SS. On the contrary, a nodular pattern with duct enlargement and microlithiasis is often observed in the disorder once known as KT. Computerised tomography and magnetic resonance imaging have lower diagnostic accuracy compared to ultrasonography $2351-56$.

Biopsy of the affected gland is necessary to formulate a diagnosis of IgG4-RS, although lip biopsy has been proposed as an alternative technique ${ }^{59}$. There are three main histopathological hallmarks for IgG4-RD: infiltrates of IgG4+ plasmacytes, intense fibrosis and obliterative phlebitis. However, the exact histological findings vary greatly depending on the tissue affected and clinical presentation. Currently, histologic diagnosis of IgG4-RD is based primarily on IgG4 positive to IgG containing cell ratio and, secondarily, on the number of IgG4 positive cells per high power field. A ratio of IgG4 to IgG that is higher than 50\% and the confirmation of at least $30 \mathrm{IgG} 4$-positive cells per high-power field are considered to be highly suggestive of IgG4-RD ${ }^{60}$.

Laboratory tests on blood can confirm the diagnosis. Patients affected by IgG4-RD show significantly higher total $\mathrm{IgG}, \mathrm{IgG} 2$, IgG4 and IgE. In addition, eosinophil counts are usually increased and hypocomplementaemia is frequent. In particular, elevated serum IgG4, even if neither present in all patients with histologically proven IgG4-RD nor specific for it, can be a supplementary tool in the diagnosis of IgG4-RD ${ }^{61}$. Serum IgG4 concentration > 135 $\mathrm{mg} / \mathrm{dl}^{-1}$ have been defined as a threshold value for diagnosis ${ }^{61}$. Furthermore, it was observed that IgG4 serum con- centration correlates with reduction of saliva production and glandular fibrosis, suggesting that $\mathrm{IgG} 4$ concentration in serum can represent a useful marker to follow the evolution of the disease and efficacy of treatment ${ }^{56}$.

In the literature, there are very few publications focusing on medical treatment of IgG4-RS, although all authors indicate systemic steroid therapy as first-line treatment and prednisone represents the most used drug. In the past decades, in fact, the good responsiveness to steroids was considered a distinctive clinical feature of MD compared to SS ${ }^{51}$.

Steroid therapy, weighted according to the activity of the disease and body mass, is usually long-term and the initial dose is gradually tapered after 2-4 weeks of starting therapy. Long-term glucocorticoid treatment seems to significantly improve symptoms related to reduced salivary secretion conferring, according to some studies, recovery of histological abnormalities. Some authors have emphasised the role of early steroid therapy to improve outcomes in patients with IgG4-RS. Salivary secretion rate, indeed, seems to decrease with histological changes related to a delayed intervention ${ }^{62}$. Conversely, the role of other immunosuppressive agents such as azathioprine, methotrexate, or mycophenolate mofetil is still controversial and understudied.

To the best of our knowledge, there are no reports about sialendoscopy performed in patients affected by IgG4 related sialadenitis. However, we believe that this technique will be useful in the management of patients suffering from IgG4-RD. Although it is unlikely that this method can replace the role of the biopsy for diagnostic purposes, sialendoscopy is a potential tool in the treatment of sialadenitis. Endoscopic techniques, in fact, as is the case 
in other chronic sialadenitis, could eliminate microlithiasis and debris thorough rinsing or using microforceps and basket, also allowing the treatment of eventual ductal stenosis using hydrostatic pressure or high-pressure balloons. Furthermore, the intraductal administration of antiinflammatory drugs, while poorly studied at present, may be an alternative to systemic steroids in the future.

\section{Conclusions}

The role of sialendoscopy in the treatment of autoimmune chronic sialadenitis is currently understudied, mainly due to the recent worldwide diffusion of this technique.

The outcomes of a few preliminary trials, however, are particularly encouraging and deserve to be verified in randomised controlled trials with a larger sample and longer follow-up period.

The discussion between otolaryngologists and rheumatologists should also be more incisive so that sialendoscopy and sialography can be considered as useful techniques for diagnosis and staging of autoimmune diseases of the salivary glands. Furthermore, rheumatologists should consider a minimally invasive technique such as interventional sialendoscopy for management of patients suffering from autoimmune diseases of the major salivary glands who do not derive benefit from conventional therapies.

\section{References}

1 Campos J, Hillen MR, Barone F. Salivary gland pathology in Sjögren's syndrome. Rheum Dis Clin North Am 2016;42:473-83.

2 Fragoulis GE, Zampeli E, Moutsopoulos HM. IgG4-related sialadenitis and Sjögren's syndrome. Oral Dis 2017;23:152-156.

3 Mulholland GB, Jeffery CC, Satija P, et al. Immunoglobulin G4-related diseases in the head and neck: a systematic review. J Otolaryngol Head Neck Surg 2015 20;44:24.

4 Fox RI. Sjögren's syndrome. Lancet 2005;366:321-31.

5 Ng WF, Bowman SJ. Primary Sjogren's syndrome: too dry and too tired. Rheumatology 2010;49:844-53.

6 Saraux A, Pers JO, Devauchelle-Pensec V. Treatment of primary Sjögren syndrome. Nat Rev Rheumatol 2016;12:456-71.

7 Reksten TR, Jonsson MV. Sjögren's syndrome: an update on epidemiology and current insights on pathophysiology. Oral Maxillofac Surg Clin North Am 2014;26:1-12.

8 Cruz-Tapias P, Rojas-Villarraga A, Maier-Moore S, et al. HLA and Sjögren's syndrome susceptibility. A meta-analysis of worldwide studies. Autoimmun Rev 2012;11:281-7.

9 Ferro F, Vagelli R, Bruni C, et al. One year in review 2016: Sjögren's syndrome. Clin Exp Rheumatol 2016;34:161-71.

${ }_{10}$ Gottenberg JE, Busson M, Loiseau P, et al. In primary Sjögren's syndrome, HLA class II is associated exclusively with autoantibody production and spreading of the autoimmune response. Arthritis Rheum 2003 48:2240-5.

11 Venables PJ. Sjögren's syndrome. Best Pract Res Clin Rheumatol 2004;18:313-29.
12 Lucchesi D, Pitzalis C, Bombardieri M. EBV and other viruses as triggers of tertiary lymphoid structures in primary Sjögren's syndrome. Expert Rev Clin Immunol 2014;10:445-55.

13 Sipsas NV, Gamaletsou MN, Moutsopoulos HM. Is Sjögren's syndrome a retroviral disease? Arthritis Res Ther 2011;13:212.

14 Brodziak A, Ziółko E, Muc-Wierzgoń M, et al. The role of human endogenous retroviruses in the pathogenesis of autoimmune diseases. Med Sci Monit 2012;18:RA80-8.

15 Fayyaz A, Kurien BT, Scofield RH. Autoantibodies in Sjögren's Syndrome. Rheum Dis Clin North Am 2016;42:419-34.

16 Vitali C, Bombardieri S, Jonsson R, et al. Classification criteria for Sjogren's syndrome: a revised version of the European criteria published by the American European consensus group. Ann Rheum Dis 2002;61:554e8.

17 Bossini N, Savoldi S, Franceschini F, et al. Clinical and morphological features of kidney involvement in primary Sjogren's syndrome. Nephrol Dial Transplant 2001;16:2328-36.

18 Davidson BK, Kelly CA, Griffiths ID. Ten year follow up of pulmonary function in patients with primary Sjogren's syndrome. Ann Rheum Dis 2000;59:709-12.

19 Vincent TL, Richardson MP, Mackworth-Young CG, et al. Sjogren's syndrome-associated myelopathy: response to immunosuppressive treatment. Am J Med 2003;114:145-8.

20 Kassan SS, Thomas TL, Montsopoulos HM, et al. Increased risk of lymphoma in sicca syndrome. Ann Intern Med 1978; 89:888-92.

21 Shiboski SC, Shiboski CH, Criswell L, et al. Sjögren's International Collaborative Clinical Alliance (SICCA) Research Groups. American College of Rheumatology classification criteria for Sjögren's syndrome: a data-driven, expert consensus approach in the Sjögren's International Collaborative Clinical Alliance cohort. Arthritis Care Res (Hoboken) 2012;64:475-87.

22 Alves M, Reinach PS, Paula JS, et al. Comparison of diagnostic tests in distinct well-defined conditions related to dry eye disease. PLoS One 2014;9:e97921.

23 Dijkstra PF. Classification and differential diagnosis of sialographic characteristics in Sjögren syndrome. Semin Arthritis Rheum 1980;10:10-7.

24 Gallo A, Benazzo M, Capaccio P, et al. Sialoendoscopy: state of the art, challenges and further perspectives. Round Table, $101^{\text {st }}$ SIO National Congress, Catania 2014. Acta Otorhinolaryngol Ital 2015;35:217-33.

25 Shacham R, Puterman MB, Ohana N, et al. Endoscopic treatment of salivary glands affected by autoimmune diseases. $\mathrm{J}$ Oral Maxillofac Surg 2011;69:476-81.

26 Pace CG, Hwang K-G, Papadaki M, et al. Interventional sialoendoscopy for treatment of obstructive sialadenitis. J Oral Maxillofac Surg 2014;72:2157.

27 Jager DJ, Karagozoglu KH, Maarse F, et al. Sialendoscopy of salivary glands affected by Sjögren syndrome: a randomized controlled pilot study. J Oral Maxillofac Surg 2016;74:1167-74.

28 De Luca R, Trodella M, Vicidomini A, et al. Endoscopic management of salivary gland obstructive diseases in patients with Sjogren's syndrome. J Craniomaxillofac Surg 2015;43:1643-9. 
${ }^{29}$ Fusconi M, Petrozza V, Schippa S, et al. Bacterial biofilm in salivary gland stones: cause or consequence? Otolaryngol Head Neck Surg 2016;154:449-53.

30 Price EJ, Rigby SP, Clancy U, et al. A double blind placebo controlled trial of azathioprine in the treatment of primary Sjogren's syndrome. J Rheumatol 1998;25:896-9.

31 Fox RI, Dixon R, Guarrasi V, et al. Treatment of primary Sjogren's syndrome with hydroxychloroquine; a retrospective, open-label study. Lupus 1996;5:31-6.

32 Kruize AA, Hene RJ, Kallenberg CG, et al. Hydroxychloroquine treatment for primary Sjogren's syndrome; a two year, double blind cross over trial. Ann Rheum Dis 1993;52:60-4.

33 Steinfeld SD, Demols P, Appelboom T. Infliximab in primary Sjogren's syndrome: one-year followup. Arthritis Rheum 2002;46:3301-3.

34 Somer BG, Tsai DE, Downs L, et al. American College of Rheumatology ad hoc Committee on Immunologic Testing Guidelines. Improvement in Sjogren's syndrome following therapy with rituximab for marginal zone lymphoma. Arthritis Rheum 2003;49:394-8.

35 Dass S, Bowman SJ, Vital EM, et al. Safety and efficacy of Rituximab in Sjogren's syndrome: results of a randomized, placebo controlled trial. Ann Rheum Dis 2007;66:70.

36 Ramos-Casals M, Brito-Zerón P, Sisó-Almirall A, et al. Topical and systemic medications for the treatment of primary Sjögren's syndrome. Nat Rev Rheumatol 2012;8:399-411.

37 Berk L. Systemic pilocarpine for treatment of xerostomia. Expert Opin Drug Metab Toxicol 2008;4:1333-40.

38 Noaiseh G, Baker JF, Vivino FB. Comparison of the discontinuation rates and side-effect profiles of pilocarpine and cevimeline for xerostomia in primary Sjögren's syndrome. Clin Exp Rheumatol 2014;32:575-7.

39 Fife RS, Chase WF, Dore RK, et al. Cevimeline for the treatment of xerostomia in patients with Sjogren syndrome: a randomized trial. Arch Intern Med 2002;162:1293-300.

40 Turner MD. Sialoendoscopy and salivary gland sparing surgery. Oral Maxillofac Surg Clin North Am 2009;21:323-9.

41 Martellucci S, Pagliuca G, de Vincentiis M, et al. Ho:Yag laser for sialolithiasis of Wharton's duct. Otolaryngol Head Neck Surg 2013;148:770-4.

42 Gallo A, Capaccio P, Benazzo M, et al. Outcomes of interventional sialendoscopy for obstructive salivary gland disorders: an italian multicentre study. Acta Otorhinolaryngol Ital 2016:479-85.

43 Marchal F, Becker M, Dulguerov P, et al. Interventional sialendoscopy. Laryngoscope 2015;125:2427-9.

44 Maresh A, Kutler DI, Kacker A. Sialoendoscopy in the diagnosis and management of obstructive sialadenitis. Laryngoscope 2011;121:495-500.

45 Chuangqi Y, Chi Y, Lingyan Z. Sialendoscopic findings in patients with obstructive sialadenitis: long-term experience. Br J Oral Maxillofac Surg 2013;51:337-41.
46 Hamano H, Kawa S, Horiuchi A. High serum IgG4 concentrations in patients with sclerosing pancreatitis. N Engl J Med 2001;344:732-8.

47 Deshpande V, Zen Y, Chan JK. Consensus statement on the pathology of IgG4-related disease. Mod Pathol 2012;25:1181-92.

48 Yamamoto M, Takahashi H, Sugai S, et al. Clinical and pathological characteristics of Mikulicz's disease (IgG4-related plasmacytic exocrinopathy). Autoimmun Rev 2005;4:195200.

49 Kitagawa S, Zen Y, Harada K, et al. Abundant IgG4-positive plasma cell infiltration characterizes chronic sclerosing sialadenitis (Küttner's tumor). Am J Surg Pathol 2005;29:783-91.

50 Kamisawa T, Nakajima H, Egawa N, et al. IgG4-related sclerosing disease incorporating sclerosing pancreatitis, cholangitis, sialadenitis and retroperitoneal fibrosis with lymphadenopathy. Pancreatology 2006;6:132-7.

51 Yamamoto M, Takahashi H, Ohara M, et al. A new conceptualization for Mikulicz's disease as an IgG4-related plasmacytic disease. Mod Rheumatol 2006;16:335-40.

52 Takano K, Yamamoto M, Takahashi H, et al. Clinicopathologic similarities between Mikulicz disease and Küttner tumor. Am J Otolaryngol 2010;31:429-34.

53 Geyer JT, Ferry JA, Harris NL, et al. Chronic sclerosing sialadenitis (Küttner tumor) is an IgG4-associated disease. Am J Surg Pathol 2010;34:202-10.

${ }^{54}$ Himi T, Takano K, Yamamoto M, et al. A novel concept of Mikulicz's disease as IgG4-related disease. Auris Nasus Larynx 2012;39:9-17.

55 Geyer JT, Deshpande V. IgG4-associated sialadenitis. Curr Opin Rheumatol 2011;23:95-101.

56 Li W, Chen Y, Sun ZP, et al. Clinicopathological characteristics of immunoglobulin G4-related sialadenitis. Arthritis Res Ther 2015;17:186.

57 Küttner H. Über entzundiche Tumoren der Submanxillarspeicheldruse. Bruns Bietr Klin Chir 1896;15:815-34.

58 Mikulicz J. Über eine eigenartige symmetrishe Erkrankung der Thränen-und Mundspeicheldrüsen. Stuttgart: Beitr. z. Chir. Festschr. f. Theodor Billroth; 1892. p. 610-630.

59 Baer AN, Gourin CG, Westra WH, Cox D, et al. Sjögren's International Collaborative Alliance. Rare diagnosis of IgG4related systemic disease by lip biopsy in an international Sjögren syndrome registry. Oral Surg Oral Med Oral Pathol Oral Radiol 2013;115:e34-9.

60 Stone JH, Zen Y, Deshpande V. IgG4-related disease. N Engl J Med 2012;366:539-51.

61 Moriyama M, Tanaka A, Maehara T, et al. T helper subsets in Sjogren's syndrome and IgG4-related dacryoadenitis and sialoadenitis: a critical review. J Autoimmun 2014;51:81-8.

62 Shimizu Y, Yamamoto M, Naishiro Y, et al. Necessity of early intervention for IgG4-related disease-delayed treatment induces fibrosis progression. Rheumatology 2013;52:679-83.

Received: September 15, 2016 - Accepted: December 12, 2016

Address for correspondence: Salvatore Martellucci, via Giulio Cesare 41/B, 04100 Latina, Italy. E-mail: dott.martellucci@ gmail.com 